\title{
Erratum to: The properties of samarium-doped zinc oxide/ phthalocyanine structure for optoelectronics prepared by pulsed laser deposition and organic molecular evaporation
}

\author{
M. Novotný ${ }^{1} \cdot$ E. Marešováa ${ }^{1,2} \cdot$ P. Fitl ${ }^{1,2} \cdot$ J. Vlček $^{1,2} \cdot$ M. Bergmann ${ }^{2}$. \\ M. Vondráček ${ }^{1} \cdot$ R. Yatskiv ${ }^{4} \cdot$ J. Bulír ${ }^{1} \cdot$ P. Hubík ${ }^{1} \cdot$ P. Hruška ${ }^{1,3} \cdot$ \\ J. Drahokoupil ${ }^{1} \cdot$ N. Abdellaoui ${ }^{5} \cdot$ M. Vrňata $^{2} \cdot$ J. Lančok $^{1}$
}

Published online: 30 March 2016

(C) Springer-Verlag Berlin Heidelberg 2016

Erratum to: Appl. Phys. A (2016) 122:225

DOI 10.1007/s00339-016-9759-6

The original version of this article unfortunately contained a mistake.

The presentation of Fig. 6 was incorrect. The correct Fig. 6 is given below.

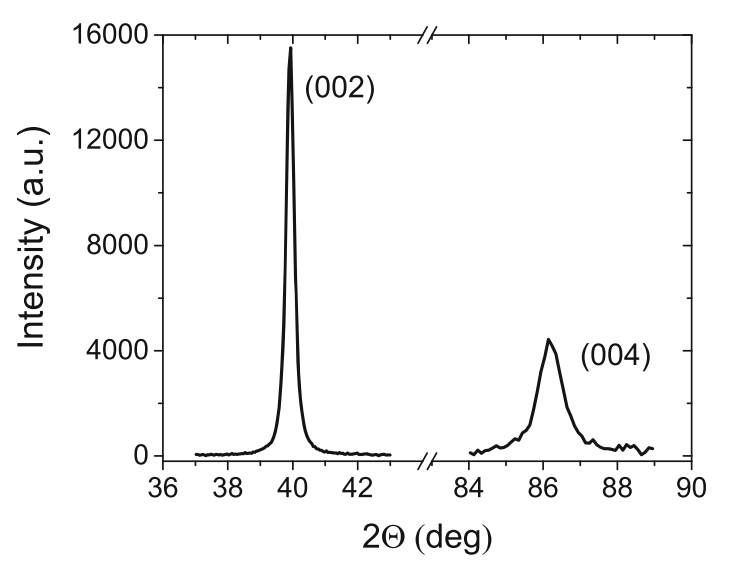

Fig. 6 XRD pattern of ZnO:Sm film deposited on silicon substrate

The online version of the original article can be found under doi:10.1007/s00339-016-9759-6.

\section{Novotný}

novotnym@fzu.cz

1 The State Institute of Physics, Czech Academy of Sciences, Na Slovance 2, 18221 Prague, Czech Republic

2 University of Chemistry and Technology, Prague, Technická 5, 16628 Prague 6, Czech Republic

3 Faculty of Mathematics and Physics, Charles University in Prague, 18000 Prague 8, Czech Republic

4 Institute of Photonics and Electronics, Czech Academy of Sciences, Chaberská 57, 18251 Prague 8, Czech Republic

5 Institut Lumière Matière, UMR5306 Université Lyon 1-CNRS, Université de Lyon, 69622 Villeurbanne Cedex, France 